José Marçal Jackson Filho ${ }^{1 *}$

Francisco de Paula Antunes Lima ${ }^{2}$ 粎

\section{Análise Ergonômica do Trabalho no Brasil: transferência tecnológica bem-sucedida?}

\author{
Ergonomic Work Analysis in Brazil: a successful \\ technological transfer?
}

${ }^{1}$ Fundação Jorge Duprat Figueiredo de Segurança e Medicina do Trabalho. Curitiba, PR, Brasil.

${ }^{2}$ Universidade Federal de Minas Gerais, Departamento de Engenharia de Produção. Belo Horizonte, MG, Brasil.

Contato:

José Marçal Jackson Filho

E-mail:

jose.jackson@fundacentro.gov.br

\footnotetext{
* Editor Científico da RBSO e editor do dossiê temático Contribuição da Análise Ergonômica do Trabalho nos desenvolvimentos da Ergonomia no Brasil.
*** Membro do Conselho Editorial da RBSO e editor do dossiê temático Contribuição da Análise Ergonômica do Trabalho nos desenvolvimentos da Ergonomia no Brasil.

Trabalho introdutório ao dossiê temático Contribuição da Análise Ergonômica do Trabalho nos desenvolvimentos da Ergonomia no Brasil. Não submetido à revisão por pares.

\begin{abstract}
Resumo
Objetivo: analisar o desenvolvimento da Análise Ergonômica do Trabalho (AET) no Brasil. Métodos: considerando-se a AET como tecnologia social, foi feita análise do processo de transferência tecnológica, comparando-se as características de seu emprego e de seu desenvolvimento na França e no Brasil. Resultados: a Ergonomia da Atividade foi introduzida no Brasil para enfrentar os problemas de condições de trabalho decorrentes do desenvolvimento industrial nos anos de 1970. No caso da França, a representação dos trabalhadores nas empresas assegura as condições sociais necessárias para a produção de conhecimentos sobre o trabalho real baseado no olhar etnográfico. No Brasil, embora prescrita na legislação, a prática da AET não está respaldada em construção social que permita a produção e o controle do uso dos conhecimentos sobre as atividades de trabalho. Observam-se, todavia, desenvolvimentos em diversas áreas, tais como no serviço público ou na indústria estatal de petróleo, e de novas metodologias a serviço da ação pública. Conclusão: embora as condições sociais para o emprego da AET sejam diferentes, a AET no Brasil tem contribuído com o campo da Saúde do Trabalhador, mas seu futuro depende de novos arranjos sociais para sustentar a prática baseada na etnografia.
\end{abstract}

Palavras-chave: Saúde do Trabalhador; Ergonomia; transferência tecnológica; análise do trabalho.

\begin{abstract}
Objective: to analyze the development of Ergonomic Work Analysis (EWA) in Brazil. Methods: considering the EWA as a social technology, an analysis of the technology transfer process was undertaken by comparing the characteristics of its employment and development in France and in Brazil. Results: Activity Ergonomics was introduced in Brazil to address working conditions problems arising from the industrial development in the 1970s. In France, the representation of employees in companies ensures the social conditions necessary for the production of knowledge at the actual work based on ethnographic approach. In Brazil, although prescribed by law, the practice of EWA is not supported by a social construction that allows the production and control of working activities knowledge. The development of new methodologies to frame the public action can be observed in several areas, such as public service or oil state industry. Conclusion: although social conditions for the EWA employment are different, EWA in Brazil has contributed to the Occupational Health field, but its future depends on the adoption of new social arrangements to support the ethnography based practice.
\end{abstract}

Keywords: occupational health; ergonomics; technological transfer; work analysis. 


\section{Introdução}

A influência da Ergonomia da Atividade, praticada nos países de língua francesa, por meio, sobretudo, da Análise Ergonômica do Trabalho (AET), é marcante para o desenvolvimento da Ergonomia no Brasil em diversos campos: profissional, de pesquisa e normativo.

Embora o referencial teórico da Ergonomia da Atividade (DANIELLOU; LAVILLE; TEIGER, 1989; GUÉRIN et al., 2001) tenha sido amplamente utilizado na pesquisa e na prática no campo da Saúde do Trabalhador e disciplinas afins, ainda não se discutiu profundamente, no âmbito da comunidade profissional do Brasil, sobre a apropriação da AET em nosso país, objeto deste dossiê da Revista Brasileira de Saúde Ocupacional.

Podemos considerar, como investiga a Antropotecnologia (WISNER, 1992), que o processo de transferência dessa "tecnologia social", inicialmente desenvolvida no seio das relações sociais da França após os turbulentos anos de 1960, foi bem-sucedido quando ela foi inserida no tecido técnico e social brasileiro? Valendo-nos dessa noção, ou seja, considerando a AET como uma "tecnologia social" transferida, vamos fazer um balanço dos desenvolvimentos da AET no Brasil.

Nessa perspectiva, iremos, inicialmente, discutir a demanda social existente no Brasil (no início dos anos de 1970) para a Ergonomia da Atividade e para a AET; em seguida, apresentar as características principais dessa "tecnologia social", para então abordar os desenvolvimentos da AET no Brasil, seus impasses e contribuições, antes de fazer a apresentação de panorama dos textos deste dossiê.

\section{Aproximações}

A introdução da Ergonomia no Brasil ocorreu em meados dos anos de 1960 de forma tardia, se comparada aos países mais industrializados, o que permitiu a ela receber influências diversas (MORAES; SOARES, 1989).

Se nos primórdios (início dos anos de 1960) estava ligada à engenharia de produtos (na então também incipiente engenharia de produção), a Ergonomia da Atividade foi convocada, nos anos de 1970, a enfrentar os problemas das condições de trabalho, diante do grande número de acidentes de trabalho decorrente do desenvolvimento industrial durante a ditadura militar ${ }^{3}$.

Durante os anos de 1970, desde o $1^{\circ}$ Seminário Brasileiro de Ergonomia em 1975, a contribuição da Ergonomia de Alain Wisner foi decisiva para o processo de institucionalização da Ergonomia e para o desenvolvimento da AET no Brasil (MORAES; SOARES, 1989).

A experiência no enfrentamento aos acidentes e às duras condições de trabalho na mineração do carvão e na siderurgia na Europa (WISNER, 1987) poderia contribuir para os problemas dos acidentes do trabalho durante o período da ditadura militar. Havia, na época, portanto, forte demanda social para experimentar em nosso país essa nova abordagem, centrada na análise do trabalho, para compreender e transformar as condições de trabalho.

Desde então, vários pesquisadores e agentes públicos brasileiros foram formados no Laboratório de Ergonomia do Conservatoire National des Arts et Métiers (CNAM), dirigido por Alain Wisner, o que foi decisivo para o desenvolvimento da AET no Brasil ${ }^{4}$. No entanto, para compreender esse processo de transferência, é necessário também analisar as condições sociais do país de origem.

\section{Características do desenvolvimento da AET no país de origem}

O desenvolvimento da Ergonomia da Atividade na França está intimamente associado à demanda social colocada pelos trabalhadores e seus representantes (WISNER, 1987): a melhoria das condições de trabalho, o reconhecimento da inteligência dos trabalhadores, a antecipação de problemas de saúde durante a introdução de novas tecnologias, os problemas musculoesqueléticos, os riscos psicossociais, dentre outras questões, mas apoiadas na legislação vigente, em especial nas leis Auroux ${ }^{5}$ (promulgadas em 1982 na França), logo no início do $1^{\circ}$ mandato do governo socialista de Mitterand. O que caracteriza a Ergonomia, assim como as disciplinas do campo do trabalho e da saúde na França, é, sobretudo, seu engajamento na compreensão e na resolução de problemas associados à questão social do trabalho (CLOT, 2010).

Esse enraizamento social da Ergonomia da Atividade nem sempre é explícito, sobretudo quando ela é ensinada como uma simples técnica de análise do

\footnotetext{
3 Ver entrevista de Franco Lo Presti Seminério, Itiro lida e de Sérgio Penna Kehl em Moraes e Soares (1989).

4 Como ilustração do impacto que essa formação produziu no Brasil, a introdução de itens sobre a AET na Norma Regulamentadora (NR) 17 (BRASIL, 2002) se deve à participação, no processo de elaboração dessa norma, de Milton Martins e Carlos Diniz Silva, na época auditores do Ministério do Trabalho e Emprego, formados no CNAM.

5 Sobre a importância dessas leis, ver Thebaud-Mony (2011).
} 
trabalho, sem considerar os processos de construção social que enquadram a construção técnica da análise.

É verdade que as técnicas de análise são conformadas, bem como qualquer outra tecnologia, por determinações sociais, como o reconhecimento do papel dos trabalhadores ao longo de toda a intervenção e análise do trabalho, da expressão da demanda à validação das recomendações.

Assim, outra característica fundamental foi a inovação metodológica ${ }^{6}$, que permitiu o desenvolvimento da AET, caracterizada pela articulação entre o uso de métodos de observação e de verbalização aliados a uma construção social (envolvimento de sindicalistas ou de delegados dos trabalhadores), pela qual se respondia à demanda de controle social e de participação dos trabalhadores nas intervenções que concernem diretamente às suas condições de trabalho (GUÉRIN et al., 2001).

De um lado, a análise de campo é guiada por um referencial teórico sobre a atividade no trabalho, baseada nos conceitos de trabalho prescrito e trabalho real (GUÉRIN et al., 2001) ou no "curso da ação" (THEUREAU, 2014); de outro, a participação ativa de sindicalistas e delegados dos trabalhadores, presentes nas empresas ${ }^{7}$, na forma de controle social das intervenções, permitiu o desenvolvimento de uma forma de "etnografia do trabalho" (LIMA, 2001) que não lesasse os trabalhadores envolvidos.

A produção de conhecimentos sobre a atividade de trabalho, oriunda do olhar etnográfico - descrição do mundo pelo olhar do outro-, permite compreender o uso do corpo, do pensamento, das emoções nas situações de trabalho, os determinantes que pesam sobre as ações dos trabalhadores, as estratégias utilizadas para atender às exigências a eles colocadas. Em suma, a AET permite uma nova lógica baseada na atividade de trabalho, pouco difundida nas empresas e instituições e que pode ser usada tanto para a prevenção quanto para melhorar o desempenho dos sistemas. Essa nova lógica implica, por exemplo, não mais na análise de acidentes em termos de erros humanos, como desvios de comportamento em relação a uma conduta segura preestabelecida, mas como falhas do processo de trabalho que precisam ser compreendidas sob o ponto de vista dos próprios atores.

Esse conhecimento sobre a realidade do trabalho pode ser usado como base para o debate social no seio das empresas, mas sob controle social (GUÉRIN et al., 2001), que é assegurado por certa construção social: requisito necessário para o uso de tais conhecimentos.

\section{A nova tecnologia na realidade brasileira: dos desenvolvimentos nos anos de 1980 aos impasses e tendências atuais}

No caso brasileiro, pode-se observar amplo desenvolvimento da AET a partir dos anos de $1980^{\circ}$, contribuindo para o enfrentamento dos problemas de saúde associados ao trabalho.

Em particular, ela surgiu como resposta metodológica apropriada diante da necessidade de enfrentar a epidemia das tenossinovites em digitadores. Abordar o problema, por meio da análise do trabalho real, criou as condições para ação conjunta envolvendo sindicalistas e agentes do Estado (pesquisadores, inspetores do trabalho, sanitaristas, dentre outros) no enfrentamento das tenossinovites (BRASIL, 2002).

Um dos efeitos positivos dessa ação foi a publicação de nova versão da Norma Regulamentadora 17 (NR-17) no início dos anos de 1990, fundamentada nos princípios da AET e que, pela primeira vez, incorporava na legislação brasileira a questão da Organização do Trabalho (BRASIL, 2002).

Criar uma norma de Ergonomia, que traduza princípios de uma disciplina cuja base é a distância entre o trabalho real e as normas que o precedem, pode parecer contraditório ou, no mínimo, um exercício inócuo de burocracia administrativa, mas não é possível negar o desenvolvimento da Ergonomia após a publicação da NR-17.

É verdade que não bastam leis e normas para mudar as condições de trabalho, mas a NR-17 serviu como instrumento para a apropriação da AET em diversas Instituições Públicas - na saúde, no trabalho ou na justiça -, na Academia e até em algumas empresas (sobretudo estatais, como a Petrobras). Mesmo o debate em torno do que constitui uma análise ergonômica que atenda aos requisitos qualitativos da norma serve para fazer avançar a compreensão da Ergonomia da Atividade e de sua diferença em relação às análises fisicalistas da relação homem-trabalho.

No entanto, nesse processo de "transferência", a AET se afasta das questões sociais e, de certa forma, assume papel marginal no desenvolvimento do campo da Saúde do Trabalhador, se comparada ao papel que desempenha na França. Além disso, a inexistência de movimento sindical forte e a insuficiência da representação dos trabalhadores nas empresas no

\footnotetext{
6 Nos anos de 1960/1970, as pesquisas na Ergonomia eram realizas em laboratório.

7 Na França, a participação dos trabalhadores não se restringe aos comitês de prevenção. Ver sobre participação dos empregados na França em Wooldridge (2002).

8 O primeiro artigo publicado na RBSO sobre a AET foi publicado em 1982 (MARCELIN; FERREIRA, 1982).
} 
Brasil (no Brasil, restrita às comissões internas de prevenção de acidentes - CIPAS e, em poucos casos, às Comissões de Fábrica) não contribuem para uma construção social adequada às intervenções, cujos resultados ficam à mercê dos gestores para serem utilizados ou engavetados.

Assim, a AET se torna uma técnica ${ }^{9}$ a serviço de especialistas e das empresas preocupadas em atender a normas e em evitar algumas perdas econômicas mais imediatas, mas pouco interessadas em intervir para enfrentar as péssimas condições de trabalho.

No caso brasileiro, a prática da AET chega a um impasse, pois é preciso se questionar:

- Como colocar a etnografia do trabalho a serviço dos trabalhadores sem a devida construção social necessária à sua proteção, validação e apropriação dos resultados?

- Como praticar AET sem fundá-la em análises da demanda legitimadas pelos diversos atores sociais, momento-chave de negociação do escopo e objeto de análise ${ }^{10}$ ?

- Além disso, diante dos processos de intensificação e precarização do trabalho, como contribuir para a melhoria das condições de trabalho, quando forças sociais e econômicas atuam em sentido contrário?

A instrumentalização da AET (enquanto técnica) não assegura as condições mínimas para sua realização nem a legitimidade garantida pela reformulação da demanda inicial. Assim, a análise do trabalho pode ser usada contra os trabalhadores, contra o desenvolvimento do próprio trabalho.

Diante de tais condições para a prática (intervenção) da Ergonomia no Brasil, sobretudo nas empresas privadas, a disciplina não tem contribuído suficientemente, como se esperava, para a melhoria das condições de trabalho. No que tange à pesquisa, todavia, observam-se contribuições importantes fundadas nos preceitos da AET, a saber:

- A concepção da metodologia da Análise Coletiva do Trabalho (FERREIRA, 1993), baseada na fala dos trabalhadores e nas discussões em grupo realizadas fora dos locais de trabalho e sem vínculo com as empresas;

- Utilização do referencial teórico-metodológico da AET para análise de acidentes industriais e do trabalho (ver dossiê "Acidentes do trabalho e sua prevenção” da RBSO de 2007) (REVISTA BRASILEIRA DE SAÚDE OCUPACIONAL, 2007), em especial o desenho do Método de Análise e Prevenção de Acidentes (MAPA), proposto por Vilela, Almeida e Mendes (2012);

- Realização de diversas pesquisas sobre a relação saúde-trabalho no setor público: saúde, educação, justiça, entre outros (ver um apanhado no ensaio de Jackson Filho neste dossiê);

- Introdução da AET e métodos de Ergonomia de projetos na indústria do petróleo (LIMA; DUARTE, 2014; DUARTE; LIMA, 2012).

A ação pública também tem se valido da AET nas suas atividades de prevenção e de proteção dos trabalhadores, como foi o caso das ações da Comissão Nacional de Ergonomia (CNE) no início dos anos de 2000 (BRASIL, 2002) ou sua aplicação em ações de vigilância (VILELA; ALMEIDA; MENDES, 2012; JACKSON FILHO; BARREIRA, 2013). Em várias oportunidades, o Ministério Público do Trabalho (MPT) tem se servido de parcerias com ergonomistas lotados em universidades (ASSUNÇÃO et al., 2006) e instituições públicas, como a Fundacentro (FERREIRA, 2011), para implementar inquéritos civis públicos em situações críticas de trabalho.

\section{Breve panorama deste dossiê}

A seu modo, este dossiê reflete algumas das tendências apontadas anteriormente, ou seja, este número, composto por seis artigos e um ensaio, é composto por quatro artigos e um ensaio voltados ao estudo do trabalho no serviço público; os outros dois artigos têm como situação de trabalho analisada o setor agrícola.

A preocupação com a relação entre trabalho e saúde no serviço público é tratada por Ferreira em Instituição Pública Federal de apoio à pesquisa. Pinto e Zambroni-de-Souza têm como objeto a atividade de motoristas de ambulância de Serviço Móvel de Urgência. Gonçalves et al. apresentam em sua pesquisa o trabalho dos profissionais de saúde pertencentes ao Núcleo de Apoio à Saúde da Família (NASF). Maciel, Santos e Rodrigues analisam as condições de trabalho de técnicos e auxiliares de saúde em unidades de saúde de Fortaleza, no Ceará. Jackson Filho, em seu ensaio, analisa e discute a contribuição da Ergonomia voltada ao trabalho no serviço público.

\footnotetext{
9 Uma técnica que a torna semelhante a outras correntes da Ergonomia próximas da higiene do trabalho e da engenharia. O perigo é reduzir o trabalho aos riscos e esforços, e o trabalhador (homem) a uma máquina - como sugere o título de uma obra de referência dessas correntes, listada por Ferreira e Donatelli (2001).

${ }^{10}$ Ver editorial de Leda Leal Ferreira neste dossiê.
} 
Nos estudos voltados ao setor agrícola, Vilela et al. estudam o trabalho no corte de cana em âmbito de ação pública interinstitucional. Abrahão, Tereso e Gemma fazem síntese de seu programa de pesquisas no campo da agricultura.

Ao contribuir com a questão da saúde e do trabalho no setor da saúde, sobretudo, e por melhores condições de trabalho na agricultura, observa-se que os pesquisadores envolvidos neste dossiê têm a questão social do trabalho em primeiro plano, assim como os princípios da AET fundamentam suas análises e seus construtos.

\section{Considerações finais}

A AET, embora não seja praticada do mesmo modo que na França, deixou um legado fundamental, como apontam os textos desta coletânea, não apenas para a Ergonomia, mas para o desenvolvimento das disciplinas que estudam a relação saúde e trabalho no Brasil: a perspectiva de agir a partir de olhar etnográfico sobre as situações de trabalho.

A perspectiva de analisar esse legado por meio das noções de "transferência de tecnologia" e de "tecnologia social” não implica apenas uma comparação termo a termo que evidencie as lacunas do contexto social brasileiro, sobretudo quanto à regulamentação social de intervenções nos locais de trabalho.

Em alguns processos de transferência de tecnologia, verdadeiras ilhas antropotecnológicas são construídas nos países acolhedores de uma tecnologia, criando o tecido social e técnico para que essa tecnologia funcione adequadamente. Para isso, é preciso recriar parte da sociedade de origem no país que recebe a tecnologia.

No caso da Ergonomia, evidentemente não podemos esperar que as relações sociais francesas, por mais que as tenhamos como referência em nossa história recente e passada, sejam adotadas no Brasil para que a Ergonomia tenha pleno desenvolvimento. Ao contrário, a Ergonomia deve se servir dessa história, de seu enraizamento social, para ajudar a construir suas próprias condições de desenvolvimento em terras estrangeiras, no caso as brasileiras, enfrentando um empresariado pouco afeito à negociação e um sindicalismo ainda fraco e pouco voltado à transformação do processo de trabalho, voluntariamente deixada sob a responsabilidade exclusiva dos gestores. Para que isso aconteça, no entanto, é necessário que tenhamos consciência das condições sociais de efetividade das intervenções ergonômicas, ou seja, da construção social que sustenta a construção técnica. Ao compreender essas inter-relações, podemos usar a AET como instrumento crítico para colocar em evidência suas próprias insuficiências enquanto "tecnologia social”.

Cabe, todavia, a nós, pesquisadores brasileiros, escolher nossos caminhos em direção ao modo como utilizá-la, seja como uma técnica, seja como um instrumento em prol da ação pública em defesa do trabalho e da saúde dos trabalhadores. Nossa opção já foi tomada.

\section{Contribuições de autoria}

Os autores contribuiram igualmente na elaboração deste ensaio introdutório.

\section{Referências}

ASSUNÇÃO, A. A. et al. Abordar o trabalho para compreender e transformar as condições de adoecimento na categoria dos teleatendentes no Brasil. Revista Brasileira de Saúde Ocupacional, São Paulo, v. 31, n. 114, p. 47-62, 2006. http://dx.doi. org/10.1590/S0303-76572006000200005.

BRASIL. Ministério do Trabalho e Emprego. Manual de aplicação da Norma Regulamentadora $n^{o}$ 17. 2. ed. Brasília: MTE, 2002.

CLOT, Y. Trabalho e poder de agir. Belo Horizonte: Editora Fabrefactum, 2010.

DANIELLOU, F.; LAVILLE, A.; TEIGER, C. Ficção e realidade do trabalho operário. Revista Brasileira de
Saúde Ocupacional, São Paulo, v. 17, n. 68, p. 7-13, 1989.

DUARTE, F. M. C.; LIMA, F. P. A. Anticiper l'activité par les configurations d'usage: proposition méthodologique pour conduite de projet. Activités, Vitry-sur-Seine, v. 9, n. 2, p. 22-47, 2012.

FERREIRA, L. L. Análise coletiva do trabalho. Revista Brasileira de Saúde Ocupacional, São Paulo, v. 21, n. 78, p. 7-19, 1993.

. Uma luta pelo reconhecimento do trabalho contra a política de redução de pessoal. Laboreal, Porto, v. 7, n. 1, p. 17-27, 2011. Disponível em: <http://laboreal.up.pt/files/articles/17_27f1_1.pdf>. Acesso em: 5 maio 2015. 
FERREIRA, L. L.; DONATELLI, S. Ergonomia: o que há para se ler em português. Ação Ergonômica, Rio de Janeiro, v. 1, n. 2, p. 25-32, 2001.

GUÉRIN, F. et al. Compreender o trabalho para transformá-lo: a prática da ergonomia. São Paulo: Edgard Blücher, 2001.

JACKSON FILHO, J. M.; BARREIRA, T. H. C. A construção da saúde do trabalhador em Piracicaba: análise da ação pública no período de 1998 a 2009. In: SIMONELLI, A. G.; RODRIGUES, D. S. (Org.) Saúde e trabalho em debate: velhas questões, novas perspectivas. Brasília, DF: Paralelo 15, 2013. p. 357392.

LIMA, F. P. A. A formação em ergonomia. In: KIEFER, C.; FAGÁ, I.; SAMPAIO, M. R. (Org.). Trabalho, educação e saúde: um mosaico em múltiplos tons. São Paulo: Fundacentro, 2001. p. 133-148.

LIMA, F. P. A.; DUARTE, F. M. C. Integrando a ergonomia ao projeto de engenharia: especificações ergonômicas e configurações de uso. Gestão $\mathcal{E}$ Produção, São Carlos, v. 21, n. 4, p. 679-690, 2014. http://dx.doi.org/10.1590/0104-530X733-13.

MARCELIN, J.; FERREIRA, L. L. Orientações atuais da metodologia ergonômica na França. Revista Brasileira de Saúde Ocupacional, São Paulo, v. 10, n. 37, p. 6469, 1982.
MORAES, A.; SOARES, M. M. Ergonomia no Brasil e no mundo: um quadro, uma fotografia. Rio de Janeiro: ABERGO, 1989.

REVISTA BRASILEIRA DE SAÚDE OCUPACIONAL. São Paulo: Fundacentro, v. 32, n. 115, 2007.

THEBAUD-MONY, A. Precarização social do trabalho e resistências para a (re) conquista dos direitos dos trabalhadores na frança. Caderno $C R H$, Salvador, v. 24, p. 23-35, 2011. Suplemento 1.

THEUREAU, J. O curso da ação: método elementar. Ensaio de antropologia enativa e ergonomia de concepção. Belo Horizonte: Editora Fabrefactum, 2014.

VILELA, R. A. G.; ALMEIDA, I. M.; MENDES, R. W. B. Da vigilância para prevenção de acidentes de trabalho: contribuição da ergonomia da atividade. Ciência e Saúde Coletiva, Rio de Janeiro, v. 17, n. 10, p. 28172830, 2012.

WISNER, A. A antropotecnologia. Estudos Avançados, São Paulo, v. 6, n. 16, p. 29-34, 1992.

. Por dentro do trabalho ergonomia: métodos e técnicas. São Paulo: FTD, 1987.

WOOLDRIDGE, F. Employee participation in France and Germany. Amicus Curiae, Londres, v. 43, n. 5, p. 26-32, 2002. 